\title{
Perceptions of graduates regarding workplace expectations: An exploratory study
}

\author{
E.E. Smith and J. Krüger \\ Department of Business Management, Nelson Mandela Metropolitan University, Vista Campus, \\ PO Box 77000, Port Elizabeth 6000, Republic of South Africa \\ Elroy.Smith@nmmu.ac.za
}

\section{Received November 2004}

\begin{abstract}
This article outlines the results of a study which investigates the perceptions of graduates regarding workplace expectations. A literature study provides a theoretical foundation which explains the nature of graduates' workplace expectations. An empirical survey was conducted, using a self-administered questionnaire, which was completed by prospective graduates at two tertiary institutions. This sample was selected in terms of the proposed restructuring of higher education institutions. Eleven null-hypotheses, investigating relationships between the dependent and independent variables, are tested by means of specific statistical methods, such as analysis of variance and correlation coefficients. The results showed highly significant differences between workplace expectations of graduates (dependent variables) and classification data (independent variables). Specific guidelines are provided to ensure the creation of more realistic graduate expectations before entering the workplace.
\end{abstract}

*To whom all correspondence should be addressed.

\section{Introduction}

According to Nel, Gerber, Van Dyk, Haasbroek, Schultz, Sono and Werner (2001:34), when individuals join an organisation they have certain expectations about promotion, salary, status, office, décor and amount of challenging work (things they expect to receive). They also have expectations about their skills, time, energy and involvement (things they expect to give). The organisation or employer also has certain expectations of what it will receive from the employee and of what it can offer the employee. This has been referred to as the 'psychological contract' between the human being as an employee and the organisation as employer. The focus of this article is, however, on the first part of this 'psychological contract' expectations of graduates regarding the workplace.

Brown (2002:1) is of the opinion that graduate expectations are too high and that graduates need to be prepared to 'take a step back before going forward.' Van Schoor (2000:41) argues that young graduates are finding it very difficult to enter the job market. Employers currently operate in a 'buyer's market' due to limited work opportunities therefore, they can pick and choose among the best prepared applicants. The identification of sought after skills, values and attitudes, will help to build an employable profile. Without adequate workplace skills, values and attitudes a person may be able to acquire theoretical knowledge and/or practical experience, however, due to limited career development potential, unrealistic expectations can be created. This article sets out to examine the expectations of graduates regarding the workplace. Firstly, a theoretical overview of graduate workplace expectations will be highlighted. Aspects such as concept clarification, factors affecting workplace expectations, previous empirical research, and employability of graduates will be outlined. Thereafter, a brief exposition of the research methodology follows. Lastly, the most important research results, conclusions and recommendations are discussed.

\section{Objectives}

The primary objective of this article is to investigate the perceptions of graduates regarding workplace expectations. To help achieve this main objective, the following secondary objectives are identified:

- To highlight the nature of graduate workplace expectations.

- To analyse the factors influencing workplace expectations.

- To empirically investigate the nature and extent of graduate workplace expectations.

- To provide guidelines to local industries regarding graduate expectations about the workplace.

- To assist graduates in developing realistic workplace expectations. 


\section{Graduate workplace expectations: A theoretical overview}

\section{Definition of concepts}

Jepson and Roizen (1985:1) define expectations as the action of mentally looking for something to take place. It is furthermore stated that expectations are reflected in both the attitudes and the consequent behaviour of employees. Expectations can also be described as wishing with confidence of fulfilment, the feeling that something is about to happen or the sum of the values of a random variable divided by the number of values (thefreedirectory.com, 2004). Robbins (2003:124) describes perception as a process by which individuals organise and interpret their sensory impressions in order to give meaning to their environment, while Boddy (2002: 581) defines it as the active psychological process in which stimuli are selected and organised into meaningful patterns. According to the World Wide Web, a graduate can be defined as a person who has received a degree from a school, where a school can be classified as a high school, college or university (Web Definition, 2004). DictionaryBarn.com (2002-2003) describes a graduate as one who has received an academic or professional degree or one who has completed the prescribed course of study in any school or institution of learning. The workplace can be an establishment, job site, or project at one geographical location containing one or more work areas or merely a place where work is done (Web Definition, 2004).

\section{Factors affecting workplace expectations}

Several factors could influence the graduate's workplace expectations. Expectations regarding rewards and benefits, personal factors, education and career, job-related and employer-related factors, ethics and social responsibility and diversity and culture, were identified. These factors are briefly outlined below.

\section{- Reward and benefit expectations}

According to Ehlers and Lazenby (2004:188), a reward system can be defined as the umbrella term for the different components in performance evaluation and the assignment of monetary and non-monetary rewards. The remunerative benefits can be classified into three main categories, namely: financial security (eg. pensions, life assurance, and personal accident insurance); financial assistance (eg. subsidised mortgages, company loans and relocation expenses) and personal benefits (eg. personal, career and retirement counselling, compassionate leave and long service awards) (Hume, 1995:157-167).

\section{- Personal expectations}

Some of the personal factors that could influence graduate work place expectations are attitudes, personality, values and norms. Robbins (2003:64) describes values as basic convictions that a specific mode of conduct or end-state of existence is personally or socially preferable to an opposite or converse mode of conduct or end-state of existence. Other personal expectations which graduates might have about the workplace are the ability to: uphold personal values; realise personal career goals and satisfy the need for job security (Beale \& Cox, 1997).

\section{- Educational and career expectations}

Hellriegel, Jackson, Slocum and Staude (2001:51-52) state that both the employee and the organisation should be committed to each other throughout the working life of the employee. Lifelong career commitment implies that job security is guaranteed as long as the employee is technically qualified and performs satisfactorily. Examples of career and educational expectations of graduates are: variety of career opportunities; provisioning of a long-term career plan; education relevance to the job situation and to receive guidance and mentoring (Bowin \& Harvey, 2001:228).

\section{- Job-related expectations}

The reason why graduates join an organisation is to do a job. According to Robbins, Odendaal and Roodt (2001:353), a job analysis is a detailed description of the tasks involved in a job (job description), indicating its relationship with other jobs and ascertaining the knowledge, skills and abilities necessary for a graduate to perform the job (job specification). Job characteristics, such as skill variety, task identity and significance, autonomy and feedback, play an important role when designing a job (Schermerhorn, Hunt \& Osborn, 1997:156). Graduates looking for a job need to pay attention to these aspects in order to ensure a proper match. Other job-related expectations that need to be considered are: location of the workplace; productivity requirements; job rotation; flexible working hours and performance feedback (Hellriegel \& Slocum, 1996).

\section{- Expectations regarding the employer}

Graduates joining an organisation have certain expectations of what they could receive from an organisation (employer) and things they expect to give to the employer (Nel et al., 2001:34). Things they could expect from an employer are among other, a meaningful and challenging job; recognition; compensation and promotion; openness and honesty; support from management; office space; induction training; team spirit and information on organisational policies and regulations. The second group of expectations is what an individual expects to offer an employer, for example: abilities and skills to execute tasks; social interaction; conforming to organisation values and goals and to maintain a good public image of the organisation.

\section{- $\quad$ Ethical and social responsibility expectations}

Post, Frederick, Lawrence and Weber (1996:90) describe business ethics as the application of general ethical ideas to business behaviour. Elhers and Lazenby (2004:44) are of the opinion that social responsibility is organisational decisionmaking that is linked to ethical values and the compliance with legal requirements and respect for communities and the environment. Specific examples of this expectation include: fair treatment; safe working environment; respect for employee rights; influence of affirmative action policies and dealing with HIV/AIDS in the workplace. 


\section{- Diversity and cultural expectations}

Thomas (1996:5) defines diversity as any mixture of items characterised by differences and similarities. Considering this definition, it should be noted that diversity is not synonymous with difference, but it encompasses differences and similarities. Workforce diversity can thus be described as a mixture of people who can vary along an infinite number of lines, such as, age, tenure, lifestyle, sexual orientation, education, experience, geographic origin, race and gender. According to Alvesson and Billing (1997:104), culture refers to an entire society or any collective within it, an organisation, a part of it or an occupation. Examples of this expectation include: cultural differences; diversity training programmes and dealing with various ethnic groups in the workplace.

\section{Previous research findings regarding graduate expectations}

Although there seems to be a lack of research conducted in South Africa regarding graduates expectations about the workplace, it appears that numerous studies have been conducted abroad. Graduate Prospects (2002:1) is of the opinion that the percentage of finalists to enter the graduate job market after university in the United Kingdom (UK) is at its lowest (it dropped from 49\% in 1998 to 39\% in 2002). Various world events negatively impacted on the confidence in the graduate recruitment market. Graduate Prospects (2003:1) further established that about $67 \%$ of first degree graduates in the UK were in employment six months after graduation, whilst only seven per cent were unemployed. These figures, however, are much gloomier for the South African labour market. An opinion poll held by the IPM Management Training and Development Corporation (2002:1) in Ottawa, revealed that $17 \%$ of recent graduates have too high expectations about their first job. Hameed (2000:1) highlights the fact that job expectations of men and women differ significantly regarding salary, other benefits and preferred organisations and sectors. Bell and Wallace (1996:1) also found that most graduates (78\%) think it will be difficult to find an education-related job. Lickindorf (2001:49) concurs that in a study at four South African universities, $56 \%$ of prospective graduates viewed their education as too broad and general and not intended to prepare them for a specific job. The role of education in preparing students for the task of earning a living was found, from an employability perspective, to be out of line with current market conditions.

\section{The employability of graduates}

Van Schoor (2000:42) further postulates that employability training should form part of a holistic student development programme which should form part of the institutional culture and also be infused into curricular activities. Tothill (2001:40) emphasises the importance of human capital and that in the light of the rapid obsolescence of skills, a capacity of life-long learning and flexibility is taking on increasing weight. There is, therefore, a need for higher education to be closely linked to the needs of the economy. Godsell (2001:1) asserts that the coming of modernity changed the nature of knowledge and the acquisition of knowledge and therefore the nature of learning was changed. Learned facts become obsolete at an increasing rate and as a result, learning has become a continuous, lifelong endeavour. Besides the nature of learning, the nature of work also changed. As a result, a degree no longer offers a passport towards employment. Creating or gaining employment will require finding a place to stand in the workplace. Bengu (2001:3) states that it 'would be naive and short-sighted to confine the human resources strategy of universities to providing skills that will enable them to secure employment or active participation in the labour force.' It should include all those activities that lay the foundation for fuller and more productive utilisation of the total human resources potential. Reassessment of the relevance of curricula is, therefore, a priority.

Van Aardt (2001:7) identifies the following paradigm shifts and policy directives in education to ensure employability of graduates: improve the earnings-generation capacity of the graduate and not merely satisfying the quest for knowledge; emphasis should be on supplying high quality, marketrelated education required by the labour market; curricula should be geared towards the acquisition of practical market-related skills and competencies; students should gain some practical work-related experience before graduating; education should not be overly knowledge-based, but rather competency and insight-based and regarding the value of entrepreneurship, focus should be placed on facilitating entrepreneurial and business skills.

Niebuhr (2001:9) also highlights that 'educating without taking careful account of economic realities and manpower needs is a luxury we can no longer afford'. A shift is required during the later school years from primarily university-orientated to a more vocational-orientated education. Deliberate efforts should be made to do justice to each subject selected by learners in terms of its particular value for the learner. Emphasis should be placed on the holistic development of a graduate to acquire general life skills. Khotseng (2001:12) is of the opinion that never in the history of human and economic development, so many people with degrees were out of employment. Degrees should be adapted to individual graduate interest, national priorities and the type of work for which there is a demand. According to Graduate Prospects (2003:1), one of the challenges facing graduates entering the workplace, is the recruitment criteria. Deployment and managing graduates with customer-orientated expectations and aspirations, who are keen to gain a return on their financial investment in studying for a degree, is yet another challenge. The following are key issues of future graduate recruitment and placement strategies: how to align graduate strategies with varied business needs for graduates; making best use of electronic recruitment; whether to develop an approach that can offer varied careers to graduates in different business areas; how to attract and develop high potential graduates; how to avoid overselling on the graduate development promise and how to develop graduates who are not on formal entry schemes. Massie (2001:1) concurs that graduate recruitment and placement schemes and agencies play a significant role in placing graduates and creating workplace and career expectations of graduates. Job security and promotion appears to be the key factors in 
attracting and retaining graduates in graduate schemes. There is some misalignment between the perceptions of graduates and agencies about recruitment and retention strategies.

\section{Hypotheses}

To investigate the relationship between the independent variables (classification data) and dependent variables (graduate expectations), various null-hypotheses are tested. The null-hypotheses addressed in this article, are the following:

$\mathrm{HO}_{1} \quad$ Gender of graduates does not differ regarding their benefit/reward expectations.

$\mathrm{HO}_{2} \quad$ Gender of graduates does not differ regarding their personal workplace expectations.

$\mathrm{HO}_{3} \quad$ Ethnic groups of graduates do not differ regarding their personal workplace expectations.

$\mathrm{HO}_{4} \quad$ Ethnic groups of graduates do not differ regarding their career/educational expectations.

$\mathrm{HO}_{5} \quad$ Ethnic groups of graduates do not differ regarding their job-related expectations.

$\mathrm{HO}_{6} \quad$ Ethnic groups of graduates do not differ regarding their employer-related expectations.

$\mathrm{HO}_{7} \quad$ Ethnic groups of graduates do not differ regarding their cultural/diversity expectations.

$\mathrm{HO}_{8} \quad$ Martial status of graduates does not differ regarding their career/education expectations.

$\mathrm{H}_{9} \quad$ Marital status of graduates does not differ regarding their employer-related expectations.

$\mathrm{HO}_{10} \quad$ Number of dependants of graduates does not differ regarding their career/educational expectations.

$\mathrm{HO}_{11}$ Expected level of income of graduates does not differ regarding their benefit/reward expectations.

The alternative hypotheses $\left(\mathrm{H}_{1}\right.$ to $\left.\mathrm{H}_{11}\right)$ can be stated as the exact opposite of the above null-hypotheses, indicating that there are differences/relationships between the variables. The reason for the inclusion of the above-mentioned hypotheses is that differences only exist between the following independent variables/classification data (gender; ethnic groups; marital status; number of dependants and level of income) and dependent variables/graduate expectations (benefit/reward; personal; career/education; job-related; employer-related and cultural/diversity). No significant differences exist between the other independent and dependent variables and were, therefore, not reported.

\section{Research methodology}

The following section provides an outline of the research methodology followed in this study.

\section{Research approach}

The quantitative research method is used in this study. It is a form of conclusive research which involves a large representative sample and structured data collection procedures are used. The quantitative research approaches used, are exploratory research (an area that has not been studied in order to develop initial ideas) and descriptive research (describe expectations of graduates).

\section{Sampling procedure}

For the purpose of this research project, the target population consists of registered, third year level (final year), business management learners at the University of Port Elizabeth (incorporating Vista University) and Port Elizabeth Technikon. The reason for the selection of this population is with reference to the proposed Nelson Mandela Metropolitan University, in terms of higher education restructuring. It is one of the aims of this study to provide industry with a comprehensive analysis of graduates needs and expectations about the workplace. The sampling frame could be specified as a printout of all registered business management learners at the abovementioned institutions, as at 15 March 2004. This clearly demarcates the field of study. A random probability sampling technique is used. The total sample size was 156.

\section{Questionnaire design}

Based on the size of the sample (156), a survey by means of self-administered questionnaires was best suited to this project. The questionnaire consists of two sections:

- Section A deals with variables regarding workplace expectations of learners. Seven workplace constructs/factors are tested, totalling 50 variables/statements. The type of ordinal scale used is a five-point Likert-type scale. One open-ended question was asked.

- Section B provides classification data (demographic characteristics) of respondents and contains a nominal scale of measurement, using categorical variables. Nine classification data variables were tested.

\section{Pilot study}

As the questionnaire has never been used previously, it was issued to six learners that are about to graduate (convenience sample). The questionnaire was also given to academics in the field of management, industrial psychology and statistics. Some problem areas were identified and suggestions for improvement were provided which ensure face validity of the questionnaire.

\section{Data collection}

The type of information required (data specification decisions) for the study can be classified as follows:

- $\quad$ Type of data - research data are numeric and nonverbal (questionnaires). 
- $\quad$ Sources of data - both secondary and primary data (survey) were collected.

- $\quad$ Nature of data - data was collected at a single point in time.

- Form of data - non-overt data by means of questionnaires.

A total of 156 questionnaires were completed by final year, business management learners, at both institutions. These questionnaires were handed out during a lecture period of the concerned classes and collected afterwards. The response rate for this survey is $49.21 \%$ (not all learners completed the questionnaires or some were absent from class).

\section{Data processing and analysis}

Returned questionnaires were inspected, edited, coded and data transferred to an Excel spreadsheet. The following are examples of techniques used during the data analysis stage of the research project: descriptive statistics; frequency distributions; factor analysis; correlation coefficients and analysis of variance.

\section{Discussion of results}

\section{Descriptive statistics}

An in-depth discussion of the descriptive statistics of the individual variables falls beyond the scope of this article. A few remarks, however, are made of those factors with significant statistics. In analysing the mean values (a measure of central tendency) of these factors, it appears that most of these values cluster around point four (agree slightly) on the instrument scale. The lowest mean score (3.97) is indicated by factor four (job related expectations) and the highest mean score (4.36) for factor two (personal expectations). None of the mean scores lies on the disagreement side of the scale. Two measures of dispersion are used, namely the standard deviation and the range. The lowest standard deviation (0.47) and range (0.33) was obtained by factor two (personal expectations), indicating that respondents do not vary too much in their responses, regarding personal expectations. The highest standard deviation and range were obtained by factor one (benefit and reward expectations), indicating that respondents varied in their responses towards this expectation.

The following section deals with the descriptive statistics of Section B of the questionnaire (classification data). Table 1 provides a graduate profile of the respondents of this study.

From Table 1, it should be noted that the categories age, number of dependants to be supported, number of experience in years and expected monthly income were recategorised for analysis purposes and are thus not exactly the same as used on the questionnaire. From the Table 1, it is evident that the majority of respondents (67\%) fall in the 19 to 22-age category. A fairly equal distribution of male and female respondents was used in the study $(49 \%$ and
$48 \%$ respectively). The majority of the respondents were from the black (54\%) and white (29\%) ethnic or population groups, which is representative of the demographics of the two higher education institutions researched. Ninety per cent of the respondents were not married, while only four per cent were married. Regarding the number of dependants that needs to be supported once employed, almost 80\% indicated that their dependants ranged from none to two. It was also found that the majority of the respondents (81\%) had working experience of none to less than two years. Although most of the respondents (31\%) indicated that they would prefer to work in a medium-sized firm, the distribution among the different employment size options were relatively close. Sixty per cent of the respondents indicated that they expect a salary between R4 000 and R6 999. A small minority (7\%) indicated an expected salary of more than R10 000 . Most of the respondents (62\%) expected to be employed within the private sector while twenty seven per cent expected to be employed in the public sector.

\section{Reliability and validity of the measuring instrument}

Internal consistency reliability is being discussed in the section dealing with factor analysis. External validity, referring to the generalisation of research results to other population groups, is ensured by means of a proper sampling procedure and clear guidelines were given regarding the place, time and conditions in which the research was conducted. The internal validity of the instrument's scores is ensured through face validity and content validity. Expert judgement and a pilot study among prospective graduates were undertaken.

\section{Factor analysis}

The SPSS statistical software package was used to conduct the factor analysis. Factors were extracted using Principle Component Analysis with Direct Oblimin rotation to allow for intercorrelations between the factors. To confirm that all items/variables load on a single factor and to explain the percentage of variance, Cronbach's alpha was calculated (refer to Table 2). The varimax rotation of factors, for the 50 graduate expectation variables, were conducted to determine the individual factor loadings, but are not reported in this article.

To establish the reliability of the various factors, Cronbach's alpha was calculated (indicating internal consistency). The reliability coefficients of Cronbach's alpha for the various factors are above 0.7 , except for career and education (A3) and job related expectations (A4), which are above 0.6. According to Hair, Anderson, Tatham and Black (1998:118), Cronbach's alpha value may be decreased to 0.6 in exploratory research. It can therefore be concluded that all factors are internally reliable. The tabled percentage of variance is the percentage of variance (of the items constituting each factor) explained by each factor. Factor one (benefits and rewards expectations), for example, explains $49.72 \%$ of the variance of the five items/variables which constitute this factor. The highest percentage of variance is indicated by the employer-related factor. 
Table 1: Frequency distribution results: A graduate profile

\begin{tabular}{|c|c|c|c|}
\hline Characteristic & Category & Amount & $(\%)$ \\
\hline Age & $\begin{array}{l}19-22 \\
23-26 \\
\text { Other } \\
\text { No response }\end{array}$ & $\begin{array}{c}105 \\
44 \\
3 \\
4\end{array}$ & $\begin{array}{c}67 \\
28 \\
2 \\
3 \\
\end{array}$ \\
\hline Gender & $\begin{array}{l}\text { Male } \\
\text { Female } \\
\text { No response }\end{array}$ & $\begin{array}{c}74 \\
77 \\
5 \\
\end{array}$ & $\begin{array}{c}48 \\
49 \\
3 \\
\end{array}$ \\
\hline Ethnic group & $\begin{array}{l}\text { Black } \\
\text { White } \\
\text { Asian } \\
\text { Coloured } \\
\text { No response } \\
\end{array}$ & $\begin{array}{c}85 \\
45 \\
7 \\
12 \\
7 \\
\end{array}$ & $\begin{array}{c}54 \\
29 \\
4 \\
8 \\
5 \\
\end{array}$ \\
\hline Marital status & $\begin{array}{l}\text { Married } \\
\text { Not married } \\
\text { No response }\end{array}$ & $\begin{array}{c}6 \\
141 \\
9 \\
\end{array}$ & $\begin{array}{c}4 \\
90 \\
6\end{array}$ \\
\hline Number of dependants & $\begin{array}{l}0-2 \\
3-5 \\
\text { No response }\end{array}$ & $\begin{array}{c}124 \\
18 \\
14 \\
\end{array}$ & $\begin{array}{c}79 \\
12 \\
9 \\
\end{array}$ \\
\hline Number of experience (years) & $\begin{array}{l}0-2 \\
3-5 \\
\text { Other } \\
\text { No response }\end{array}$ & $\begin{array}{c}126 \\
17 \\
1 \\
12\end{array}$ & $\begin{array}{c}81 \\
11 \\
1 \\
7\end{array}$ \\
\hline Employment size of expected employer & $\begin{array}{l}\text { Small } \\
\text { Medium } \\
\text { Large } \\
\text { Self-employed } \\
\text { No response } \\
\end{array}$ & $\begin{array}{l}41 \\
48 \\
38 \\
10 \\
19 \\
\end{array}$ & $\begin{array}{c}26 \\
31 \\
25 \\
6 \\
12 \\
\end{array}$ \\
\hline Expected monthly income & $\begin{array}{l}\text { R1 000-R3 } 999 \\
\text { R4 000-R6 } 999 \\
\text { R7 000-R9 } 999 \\
\text { Other } \\
\text { No response }\end{array}$ & $\begin{array}{l}28 \\
94 \\
10 \\
11 \\
13 \\
\end{array}$ & $\begin{array}{c}18 \\
60 \\
7 \\
7 \\
8 \\
\end{array}$ \\
\hline Expected employment sector & $\begin{array}{l}\text { Private } \\
\text { Public } \\
\text { Both } \\
\text { No response } \\
\end{array}$ & $\begin{array}{c}96 \\
41 \\
7 \\
11 \\
\end{array}$ & $\begin{array}{c}62 \\
27 \\
4 \\
7 \\
\end{array}$ \\
\hline
\end{tabular}

Table 2: Cronbach's alpha for Section A of the questionnaire

\begin{tabular}{c|l|c|c}
\hline Items/Variables & \multicolumn{1}{|c|}{ Factor } & Cronbach's Alpha & \% of Variance \\
\hline $1-5$ & Rewards and benefits (A1) & 0,75 & 49,72 \\
\hline $6-13$ & Personal (A2) & 0,74 & 52,30 \\
\hline $14-21$ & Career and education (A3) & 0,66 & 56,48 \\
\hline $22-29$ & Job-related (A4) & 0,69 & 50,21 \\
\hline $30-37$ & Employer-related (A5) & 0,84 & 61,34 \\
\hline $38-45$ & Ethics and social responsibility (A6) & 0,75 & 57,48 \\
\hline $46-50$ & Culture and diversity (A7) & 0,81 & 57,99 \\
\hline
\end{tabular}

\section{Correlation}

An inter-item correlation exercise was conducted to determine the correlation between the variables which constitute each factor. It appears that almost all of the variables in each factor show strong positive relationships with each other. A positive correlation coefficient $(r$ value) indicates a strong or positive relationship among the variables. Only two variables which showed a negative/reverse relationship were in the career and education factor, namely previous job experience $(-0.3166)$ and starting at the bottom of the hierarchy (-0.1048). All other variables constituting the factors indicated strong inter-item correlation.

\section{ANOVA}

The purpose of this analysis is to investigate the relationship between the independent variables (classification data) and dependent variables (graduate expectations) and to test the stated hypotheses. Inferential statistics are used to make inferences about the population using sample data and to make decisions about various hypotheses. According to Blalock (1981:335), analysis of variance can be used to test for differences among means and cultivates a structure of simultaneous relationships among two or more phenomena. With regard to the ANOVA exercise, it reveals that relationships only exist between the following independent variables (classification data) and the dependent variables 
(expectations): gender; ethic group; marital status; number of dependants and level of income. No significant relationships existed between the following classification data variables (independent) and expectation variables (dependent) and were therefore excluded from the ANOVA results and not reported: age; experience, employment size and sector of employment. The results of analysis of variance tests are given in Table 3 .

The ANOVA results clearly indicate the relationships between the independent variables and graduate expectations (dependent variables). The null hypotheses $\left(\mathrm{HO}_{1}\right.$ to $\left.\mathrm{HO}_{11}\right)$ can, in all cases, be rejected at a significance level of 0,01 . $\mathrm{HO}_{1}$ falls within the rejection region $(\mathrm{p}<$ 0,01 ), which indicates that there is a significant relationship (difference) between gender and benefit/reward expectations of graduates $\left(\mathrm{H}_{1}\right.$ accepted). The larger F-statistic of 7,830 and P-value of 0,006 show that there are a significant relationship (difference) between gender and personal expectations of graduates. The null hypothesis, $\mathrm{H}_{2}$, can therefore be rejected and the research hypothesis $\left(\mathrm{H}_{2}\right)$ can be accepted. The third null hypothesis $\left(\mathrm{HO}_{3}\right)$ can also be rejected, based on the F-statistic of 7,244 and P-value of 0,000 . There is a highly significant relationship (difference) between ethic groups and personal expectations of graduates $\left(\mathrm{H}_{3}\right.$ accepted). Based on the F-statistic of 11,845 and Pvalue of $0,000, \mathrm{HO}_{4}$, can be rejected $(\mathrm{p}<0,01)$. The research hypothesis, $\mathrm{H}_{4}$, can be accepted: there is a highly significant relationship between ethnic groups and career/education expectations of graduates. $\mathrm{H}_{5}$ can be rejected $(\mathrm{p}<0,01)$ and the research hypothesis $\left(\mathrm{H}_{5}\right)$ can be accepted. There is a significant relationship (difference) between ethnic groups and job-related expectations of graduates. The P-value of 0,000 and F-statistic of 9,485 rejects the null hypothesis, $\mathrm{HO}_{6}$, and indicates that ethnic groups differ in their expectations regarding the employer ( $\mathrm{H}_{6}$ accepted). There also appears to be a highly significant relationship (difference) between ethnic groups and cultural/diversity expectations of graduates $\left(\mathrm{H}_{7}\right.$ accepted) $\mathrm{HO}_{7}$ can be rejected, based on the F-statistic of 9,355 and Pvalue of 0,000 . The null hypothesis, $\mathrm{HO}_{8}$, is rejected at a significance level of 0,01 (P-value is 0,000 and F-statistic is 16,331). There is a highly significant relationship (difference) between marital status and career/education expectations of graduates $\left(\mathrm{H}_{8}\right.$ accepted). It also appears that graduates with different marital status, differ in their expectations about the employer. $\mathrm{H}_{9}$, could therefore be rejected $(\mathrm{p}<0,01)$ and the research hypothesis, $\mathrm{H}_{9}$, could be accepted. $\mathrm{H}_{10}$, can be rejected, based on the F-statistic of 3,373 and $\mathrm{P}$-value of $0,007\left(\mathrm{H}_{10}\right.$ accepted $)$. There is a significant relationship (difference) between number of dependants and career/education expectations of graduates. The last null hypothesis, $\mathrm{H} 0_{11}$, falls within the rejection region ( $\mathrm{p}<0,01)$. The expected level of income of graduates is related to their benefit/reward expectations $\left(\mathrm{H}_{11}\right.$ accepted)

Further post-hoc tests, (eg. Scheffé's test) was conducted, but not reported, as this is an exploratory study and it falls beyond the scope of this article.

\section{Conclusions and recommendations}

It appears that the psychological contract that exists between the human being as an employee and the organisation as employer plays an important and fundamental role that directs employment relations in the organisation. Both the employee and employer have certain expectations about each other - what they can offer and what they want to receive. Secondary research revealed that graduate expectations about the workplace are often too high and not realistic. For analysis purposes and the focus of this article, the following graduate workplace expectations were identified: benefit/reward; personal; career/educational; jobrelated; employer-related; cultural/diversity and ethical/social responsibility expectations. These expectations were empirically tested. The following conclusions and recommendations can be drawn, based on the analysis of variance between the independent variables (classification data) and dependent variables (graduate expectations):

- $\quad$ There appears to be a highly significant relationship between gender and benefit/reward expectations of graduates $\left(\mathrm{H}_{1}\right.$ rejected). Differences exist between males and females regarding benefit/reward expectations. Employers should realise that because of gender differences, prospective employees have different expectations about benefits/rewards in the workplace.

- Gender differences are also reflected in personal expectations of graduates regarding the workplace $\left(\mathrm{HO}_{2}\right.$ rejected). Employment policies and practices of the employer should make provision for the differences in the personal expectations of males and females.

- Highly significant relationships were found between ethnic groups and various graduate expectations $\left(\mathrm{HO}_{3}\right.$ to $\mathrm{H}_{7}$ rejected). Ethnic groups differ regarding the following expectations: personal; career/educational; job-related; employer-related and cultural/diversity expectations. Employers should be sensitive and open towards differences between ethnic groups and the fore-mentioned graduate workplace expectations. Contemporary organisations should, therefore, without becoming too ethnically or race-orientated, attempt to cater for and align ethnic differences with these workplace expectations.

- The marital status of graduates showed highly significant relationships with the career/educational expectations and employer-related expectations of graduates $\left(\mathrm{HO}_{8}\right.$ and $\mathrm{H}_{9}$ rejected respectively). Graduates with different marital status do not have the same expectations about their career and prospective employer. Career opportunities and training provided by the organisation should reflect differences in marital status of employees.

- The number of dependants to be supported by the graduate, once employed, indicated highly significant differences with career/educational expectations $\left(\mathrm{H}_{10}\right.$ 
rejected). Prospective employers should realise that employees differ in their expectations about their career/education, based on the number of dependants to be supported.

- Graduates' expected level of income showed highly significant relationships with benefit/reward expectations $\left(\mathrm{HO}_{11}\right.$ rejected). The level of income expected by employees is directly related to other benefits/rewards expected. Unrealistic expected levels of income may lead to unrealistic expectations of other benefits/rewards.
Table 4 provides specific guidelines and recommendations that could be used by both industry and graduates to ensure realistic workplace expectations.

The following extract by Khoapa (2001:46) is appropriate with which to conclude this article:

\begin{abstract}
'... for many years the course of study was shaped by the authority of tradition and seldom challenged. A reconstruction of curricula requires the review of intellectual, aesthetic and philosophical experiences that enters the lives of graduates.'
\end{abstract}

Table 3: Analysis of variance for graduate expectations and the independent variables (classification data)

\begin{tabular}{l|l|r|r|r|r}
\hline \multirow{2}{*}{$\begin{array}{l}\text { Independent } \\
\text { Variables }\end{array}$} & \multicolumn{1}{|c|}{ Dependent variables } & Sum of squares & Df & F-test & P-value \\
\hline \multirow{2}{*}{ Gender } & Benefit/reward expectations & 9,883 & 1 & 10,930 & 0,001 \\
\cline { 2 - 6 } & Personal expectations & 4,005 & 1 & 7,830 & 0,006 \\
\hline \multirow{2}{*}{ Ethnic group } & Personal expectations & 10,358 & 3 & 7,244 & 0,000 \\
\cline { 2 - 6 } & Career expectations & 14,737 & 3 & 11,845 & 0,000 \\
\cline { 2 - 6 } & Job-related expectations & 18,995 & 3 & 4,562 & 0,004 \\
\cline { 2 - 6 } & Employer-related expectations & 22,317 & 3 & 9,485 & 0,000 \\
\cline { 2 - 6 } & Culture/diversity expectations & 19,153 & 3 & 9,355 & 0,000 \\
\hline \multirow{2}{*}{ Marital status } & Career/education expectations & 12,106 & 1 & 16,331 & 0,000 \\
\cline { 2 - 6 } & Employer-related expectations & 3,471 & 1 & 8,335 & 0,004 \\
\hline No. of dependants & Career/education expectations & 10,520 & 5 & 3,373 & 0,007 \\
\hline Level of income & Benefit/reward expectations & 12,470 & 6 & 3,031 & 0,008 \\
\hline
\end{tabular}

Table 4: Guidelines and recommendations to ensure realistic expectations of graduates before entering the workplace

\begin{tabular}{l|l}
\hline 1 & $\begin{array}{l}\text { Strategies that could be used to bridge the gap between graduate expectations and the realities of the workplace are: vacation } \\
\text { employment for undergraduates; high school outreach programmes by organisations; reality projects for final year students; } \\
\text { workshops, lectures and seminars at schools and universities on business-related issues. }\end{array}$ \\
\hline 2 & Employability training should be included in student development programmes. \\
\hline 3 & Because of the rapid obsolescence of skills, a capacity of life-long learning and flexibility should be created. \\
\hline 4 & There is a need for higher education which is closely linked to the needs of the economy. \\
\hline 5 & $\begin{array}{l}\text { Due to the fact that the nature of learning and the nature of work has changed, a degree no longer offers a passport towards } \\
\text { employment. Creating or gaining employment will require finding a place to stand in the workplace. }\end{array}$ \\
\hline 6 & $\begin{array}{l}\text { Attempts should be made to improve the earnings-generation capacity of the graduate and not merely satisfying the quest for } \\
\text { knowledge. }\end{array}$ \\
\hline 8 & Emphasis should be on supplying high quality, market-related education required by the labour market. \\
\hline 9 & Students should gain some practical work-related experience in the world of work before graduating. \\
\hline 10 & Education should not be overly knowledge-based, but rather competency- and insight-based. \\
\hline 11 & Regarding the value of entrepreneurship, focus should be placed on teaching entrepreneurial and business skills. \\
\hline 12 & $\begin{array}{l}\text { Graduate placement strategies should focus on how to: align graduate strategies with varied business needs for graduates; making } \\
\text { best use of e-recruitment; avoid overselling on the graduate development promise and how to develop graduates who are not on } \\
\text { formal entry schemes. }\end{array}$ \\
\hline
\end{tabular}

\section{References}

Alvesson, M. \& Billing, Y.D. 1997. Understanding gender and organisations. London: SAGE.

Beale, R.L. \& Cox, T. (Jr.). 1997. Developing competency to manage diversity. San Francisco: Berret-Koehler Publishers, Inc.
Bell, S. \& Wallace, D.C. 1996. 'Initial employment experiences of Art graduates: Preliminary results’. [online] URL:http://www.cirpa-acpri.ca/prevConferences/ calgary96/96_proceedings/student-satisfaction/sld010.htm.

Bengu, S.M. 2001. 'The role of universities in the training for employment', Africa 2001, 2(1), 3-6.

Blalock, H.M. 1981. Social statistics. Auckland: McGrawHill Book Company. 
Boddy, D. 2002. Management: An introduction. London: Pearson Education Ltd.

Bowin, R.B. \& Harvey, D. 2001. Human resource management: An experimental approach. New Jersey: Prentice Hall, Inc.

Brown, A. 2002. 'Experience key to jobs as graduates' image takes a fall'. [online] URL: http://news. scotsman.com/scotland.cfm?id=94842004.

DictionaryBarn.com. 2002-2003. [online] URL:http://www. dictionarybarn.com/GRADUATE.php.

Ehlers, T. \& Lazenby, K. 2004. (Eds.). Strategic management: Southern African concepts and cases. Pretoria: Van Schaik Publishers.

Godsell, B. 2001. 'The arts graduate and the new South Africa’, Africa 2001, 2(1):1-2.

Graduate Prospects. 2002. 'Students' career plans, aspirations and expectations (Summer 02)'. [online] URL:www.prospects.ac.uk/.../students_career_plans_aspirat ions_and_expectations_summer_02/p!ebxdkl.

Graduate Prospects. 2003. 'Graduate schemes - a changing picture (Winter 03)'. [online] URL:www.prospects. ac.uk/cms/ShowPage/..._a_chaning_pricture_Winter_03_/p! edXXX.

Hair, J.F., Anderson, R.E., Tatham, R.L. \& Black, W.C. 1998. Multivariate data analysis. New Jersey: Prentice Hall, Inc.

Hameed, N. 2000. 'WetFeet: Job expectations differ for men and women'. [online] URL:http://www.wetfeet.com/ about/pressreleases/studies_male_female.asp.

Hellriegel, D., Jackson, S.E., Slocum, J. \& Staude, G. 2001. Management. Cape Town: Oxford University Press Southern Africa.

Hellriegel, D. \& Slocum, J.W. (Jr.). 1996. Management. Ohio: South-Western College Publishing.

Hume, D.A. 1995. Reward management: Employee performance, motivation and pay. Massachusetts: Blackwell Publishers, Inc.

IPM Management Training and Development Corporation. 2002. 'Graduates' Expectation Survey: Poll'. [online] URL:http://www.workplace.ca/opinionpoll/opin_arch083.ht $\mathrm{ml}$.

Jepson, N. \& Roizen, J. 1985. Degrees for jobs: Employer expectations of higher education. Surrey: SRHE \& NFERNelson.

Khoapa, B.A. 2001. 'The BA degree revisited', Africa 2001, 2(1):46-48.
Khotseng, B.N. 2001. 'BA graduates and educational needs of today and tomorrow’, Africa 2001, 2(1):12-15.

Lickindorf, E. 2001. 'Some BA student attitudes and expectations: Questionnaire results', Africa 2001, 2(1):4953.

Massie, S. 2001. 'About staff: Work ethic, desire key for recent graduates'. [online] URL: wysiwyg://main.121/ http://www.calgarysun.com/perl-bin/niveau2.cg.

Nel, P.S., Gerber, P.D., Van Dyk, P.S., Haasbroek, G.D., Schultz, H.B., Sono, T. \& Werner, A. 2001. Human resources management. Cape Town: Oxford University Press Southern Africa.

Niebuhr, G.A. 2001. 'Tertiary education with specific reference to the BA degree: A policy perspective', Africa 2001, 2(1):9-11.

Post, J.E., Frederick, W.C., Lawrence, A.T. \& Weber, J. 1996. Business and society: Corporate strategy, public policy and ethics. New York: McGraw-Hill, Inc.

Robbins, S.P. 2003. Organizational behaviour. New Jersey: Prentice Hall, Inc.

Robbins, S.P., Odendaal, A. \& Roodt, G. 2001. Organisational behaviour: Global and Southern African perspectives. Cape Town: Pearson Education South Africa.

Schermerhorn, J.R. (Jr.), Hunt, J.G. \& Osborn, R.N. 1997. Organizational behavior. New York: John Wiley \& Sons, Inc.

thefreedirectory.com. 2004. [online] URL:http://www. thefreedictionary.com/expectation.

Thomas, R.R. (Jr.). 1996. Redefining diversity. New York: Amacon.

Tothill, A. 2001. 'Higher education and employment in the OECD: Lessons for South Africa?’ Africa 2001, 2(1):40-45.

Van Aardt, C. 2001. 'The labour market, the needs of the economy, and the humanities', Africa 2001, 2(1), 7-8.

Van Schoor, W.A. 2000. 'What they don't teach you at university: Skills, values, and attitudes for the South African workplace', South African Journal of Education, 20(1): 4146.

Web Definition. 2004. [online] URL:http://www. cogsci.princeton.edu/sci-bin/webwn. 